\title{
Mycorrhizal Colonization Variation Produced by Mulching and Zinc Sulphate Overlapped on Differentiated Fertilization
}

\author{
Vlad STOIAN ${ }^{1}$, Roxana VIDICAN ${ }^{1 *}$, Ioan ROTAR ${ }^{1}$, Florin PĂCURAR ${ }^{1}$ \\ ${ }^{1)}$ Faculty of Agriculture. University of Agriculture and Veterinary Medicine Cluj, 3-5 Calea Mănăștur str., \\ 400372, Cluj-Napoca, Romania \\ * corresponding author: roxana.vidican@usamvcluj.ro_.
}

Bulletin USAMV series Agriculture 71(2)/2014

Print ISSN 1843-5246; Electronic ISSN 1843-5386

DOI 10.15835/buasvmcn-agr: 10843

\begin{abstract}
Vesicular arbuscular mycorrhizas act in the rhizosphere of plants as regulators of the processes of absorption and transfer of nutrients. High absorption potential show the involvement in nutrients cycle, reducing nutrient losses across the entire ecosystem and enhancing host plant resistance to stress factors. High biodiversity of grassland ecosystems is susceptible to the type of fertilization and maintenance of the land, climate contributing to the accentuation of plants sensitivity. The use of substances based on zinc in order to increase the root system of the plants and at the same time the surface on which will be established mycorrhizal fungi, or mulching, as an alternative to mowing, can act as stabilizers of the effect produced by mineral or organo-mineral fertilizers. Under the same fertilization conditions zinc sulfate acts, generally, to double the intensity and the colonization degree compared to mulching, and the maximum frequency is obtained only in the case of zinc sulphate application.
\end{abstract}

Keywords: fertilization, mycorrhizal colonization, treatment, disturbances

\section{INTRODUCTION}

Vesicular arbuscular mycorrhizas act in the rhizosphere of plants as regulators of the processes of absorption and transfer of nutrients. The main characteristics of these microorganisms are the ablility to access remote areas from the root due to the expansion of extraradicular mycelium, the absorption of less mobile elements and a high potential of transfer to plants they colonize as intraradicular symbionts developing for this process special structures called arbuscules inside root cells (Dörmann et al., 2014, Ehrmann and Ritz, 2013). Evolution of mycorrhizas with plants strengthened the balance of ecosystems, especially those defined by high biodiversity. High absorption potential show the involvement in nutrients cycle, reducing nutrient losses across the entire ecosystem and enhancing host plant resistance to stress factors (Birhane et al., 2012, Goh et al., 2013, Hodge and Storer, 2014).

In the context of climate depreciation and destabilization of ecosystem functioning by altering the applied management, intensification or, in contrast, land abandonment, the response of mycorrhizas to these disturbing factors can be an important component in forecasting models of ecosystem transforming.

High biodiversity of grassland ecosystems is susceptible to the type of fertilization and maintenance of the land, climate contributing to the accentuation of plants sensitivity. The use of substances based on zinc in order to increase the root system of the plants and at the same time the surface on which will be established mycorrhizal fungi, or mulching, as an alternative to mowing, can act as stabilizers of the effect produced by mineral or organo-mineral fertilizers, which will replace traditional organic fertilization, for keeping the high biodiversity values.

\section{MATERIALS AND METHODS}

To study the stabilizing effect of mulching and application of zinc sulphate overlapped on fertilization, was installed in 2009 an experimental 
field in Ghețari village, Alba County, Romania, and the sampling period was during 2010-2011. Variants included in the experiment represented six different fertilization recipes, graduation starting from an unfertilized control (F1) and continuing with a variant with manure (F2 - $10 \mathrm{t} /$ ha), a variant of organo-mineral fertilization (F3 $10 \mathrm{t} / \mathrm{ha}$ manure $+50 \mathrm{~kg} / \mathrm{ha} \mathrm{N}_{2}$ ) and three variants of mineral fertilization (F4 - NPK 50:25:25 kg/ha, V5 - Eurofertil mezocalc $120 \mathrm{~kg} / \mathrm{ha}+50 \mathrm{~kg} / \mathrm{ha} \mathrm{N}_{2}$ and F6 - Eurofertil mezocalc $120 \mathrm{~kg} / \mathrm{ha}$ ). Mycorrhizal colonization parameters (freq - Frequency\% int - Intensity\%, cdeg - colonization degree \%) were observed in the root system of Festuca rubra plants, dominant grass in the studied grassland ecosystem, and sampling date was the end of vegetation period.

Analysis of experimental data was performed using constrained ordination RDA (redundancy analysis) integrated in $\mathrm{R}$ Statistics software ( $\mathrm{R}$ Core Team, 2014), package "vegan" (Oksanen et al., 2013) and post-hoc tests type LSD integrated statistical software (StatSoft, 2012).

\section{RESULTS AND DISCUSSION}

Application of zinc sulphate over fertilization recipes with mineral nitrogen proved beneficial for installation of mycorrhizal fungi in the roots of Festuca rubra, combination NPK (F4) with zinc sulfate mentaining the degree of colonization and intensity more than $12 \%$, and for fertilization based on Eurofertil mezocalc supplemented with nitrogen (F5) were recorded values close to $22 \%$, the frequencies of both variants are located around $100 \%$. (Tab. 1). Fertilization recipes without mineral nitrogen (F6) or just manure (F2) in the presence of zinc sulfate reduces colonization values below $1 \%$ and the frequency at $60 \%$, respectively $35 \%$, a phenomenon explained by reduced production of fresh roots, the senescent not being favorable for mycorrhizal fungi.

Following the trend identified in the application zinc sulfate, mulching in combination with manure supplemented with mineral nitrogen (F3) or use a recipe with an amount of mineral nitrogen double than phosphorus and potassium (F4) stimulates achieving a value of $9-10 \%$ of colonization degree and intensity, overlapped on a frequency higher than $90 \%$ (Tab. 1). The lowest values of the colonization parameters are identified at the variants fertilized with manure (F2) and Eurofertil mezocalc (F6).

For all the three colonization parameters analyzed, treatment of zinc sulfate or mulching can produce strong variations (Tab. 1). Compared to the variant fertilized with Eurofertil mezocalc and mineral nitrogen (F5), all mulched experimental variants were recorded significant differences, the degree of colonization and intensity was much lower. In contrast, compared to mulching application of zinc sulphate over F5 fertilization produced significant increase in frequency only at the unfertilized variant (F1), variant fertilized with manure (F2) and variants fertilized with Eurofertil mezocalc (F5 and F6).

At the level of colonization degree were recorded most of the significant differences between the experimental variants fertilized and mulched or fertilized and treated with zinc sulfate (Tab. 1). Compared to the NPK fertilized variants (F4) and manure supplemented with mineral nitrogen (F3), over which was applied zinc sulfate, most mulched variants recorded significant differences, phenomenon also observed in the control variant (F1) and treated with sulphate zinc compared to mulched variants F1, F2, F5 and F6.

Overall, mulching decreases the degree of colonization and the intensity, but colonization frequency remains at a level higher than $50 \%$, while zinc sulphate is acting much more restrictive depending on the recipe of the fertilizer (Tab. 1).

In the case of management by mulching, the strongest disturbances of colonization frequency are produced by fertilization with manure (F2) or Eurofertil mezocalc (F6), a phenomenon explained by overlapping factors of climate and fertilization on RDA ordination chart, where the frequency is placed on the trajectory that show increasing in the amount of nitrogen applied (Fig. 1, Tab. 2). The lack of accessible nitrogen to plants in F2 and F6 fertilization recipes, caused a decrease in the rate of branching in Festuca rubra root system, reducing the space available for the establishment of new points for mycorrhizal colonization.

For the degree of colonization, mulching is beneficial when it overlaps on a mineral fertilization easily accessible for plants, localization of parameter in the ordination graph being in the action area of fertilization with manure supplemented with mineral nitrogen (F3) and fertilization with NPK (F4 ) (Fig. 1). Colonization 
Tab. 1. Interaction effect of experimental factors on the parameters of colonization in roots of Festuca rubra

\begin{tabular}{|c|c|c|c|c|c|c|c|c|}
\hline \multirow[t]{2}{*}{ Manag } & \multirow{2}{*}{\multicolumn{2}{|c|}{ Parameter }} & \multicolumn{6}{|c|}{ Zinc sulphate } \\
\hline & & & $\mathrm{F} 1$ & $\mathrm{~F} 2$ & F3 & $\mathrm{F} 4$ & F5 & F6 \\
\hline & & Cdeg \% & 10.39 & 0.16 & 7.69 & 12.18 & 21.85 & 0.89 \\
\hline \multirow{8}{*}{ mulch } & $\mathrm{F} 1$ & 5.13 & $0.001^{* * *}$ & $0.001^{* * *}$ & $0.002 * *$ & $0.001^{* * *}$ & $0.001^{* * *}$ & $0.001^{* * *}$ \\
\hline & $\mathrm{F} 2$ & 0.65 & $0.001^{* * *}$ & 0.542 & $0.001^{* * *}$ & $0.001^{* * *}$ & $0.001^{* * *}$ & 0.757 \\
\hline & F3 & 9.91 & 0.546 & $0.001^{* * *}$ & $0.007^{* *}$ & $0.006^{* *}$ & $0.001^{* * *}$ & $0.001^{* * *}$ \\
\hline & $\mathrm{F} 4$ & 9.01 & 0.089 & $0.001^{* * *}$ & 0.104 & $0.001^{* * *}$ & $0.001 * * *$ & $0.001^{* * *}$ \\
\hline & F5 & 5.09 & $0.001^{* * *}$ & $0.001^{* * *}$ & $0.002 * *$ & $0.001^{* * *}$ & $0.001^{* * *}$ & $0.001^{* * *}$ \\
\hline & F6 & 0.51 & $0.001^{* * *}$ & 0.663 & $0.001 * * *$ & $0.001^{* * *}$ & $0.001^{* * *}$ & 0.629 \\
\hline & & & \multicolumn{6}{|c|}{ Zinc sulphate } \\
\hline & & Freq $\%$ & 89.44 & 35.00 & 75.00 & 98.33 & 100.00 & 60.00 \\
\hline \multirow{8}{*}{ mulch } & $\mathrm{F} 1$ & 75.56 & $0.003 * *$ & 0.000 & 0.901 & 0.000 & 0.000 & 0.001 \\
\hline & $\mathrm{F} 2$ & 50.58 & 0.000 & 0.001 & 0.000 & 0.000 & 0.000 & $0.039 *$ \\
\hline & F3 & 91.11 & 0.710 & 0.000 & 0.001 & 0.112 & 0.051 & 0.000 \\
\hline & F4 & 96.11 & 0.141 & 0.000 & 0.000 & 0.621 & 0.388 & 0.000 \\
\hline & $\mathrm{F} 5$ & 82.78 & 0.141 & 0.000 & 0.087 & 0.001 & 0.000 & 0.000 \\
\hline & F6 & 55.56 & 0.000 & 0.000 & 0.000 & 0.000 & 0.000 & 0.324 \\
\hline & & & \multicolumn{6}{|c|}{ Zinc sulphate } \\
\hline & & Int $\%$ & 11.44 & 0.43 & 10.17 & 12.38 & 21.85 & 1.47 \\
\hline \multirow{6}{*}{ mulch } & F1 & 6.58 & $0.001^{* * *}$ & $0.001^{* * *}$ & $0.001^{* * *}$ & $0.001^{* * *}$ & $0.001^{* * *}$ & $0.001^{* * *}$ \\
\hline & $\mathrm{F} 2$ & 1.24 & $0.001^{* * *}$ & 0.203 & $0.001 * * *$ & $0.001^{* * *}$ & $0.001^{* * *}$ & 0.719 \\
\hline & F3 & 10.84 & 0.343 & $0.001^{* * *}$ & 0.293 & $0.017^{*}$ & $0.001^{* * *}$ & $0.001^{* * *}$ \\
\hline & $\mathrm{F} 4$ & 9.37 & $0.002 * *$ & $0.001^{* * *}$ & 0.208 & $0.001^{* * *}$ & $0.001^{* * *}$ & $0.001^{* * *}$ \\
\hline & F5 & 6.14 & $0.001^{* * *}$ & $0.001^{* * *}$ & $0.001^{* * *}$ & $0.001^{* * *}$ & $0.001^{* * *}$ & $0.001^{* * *}$ \\
\hline & F6 & 0.89 & $0.001^{* * *}$ & 0.472 & $0.001^{* * *}$ & $0.001^{* * *}$ & $0.001^{* * *}$ & 0.359 \\
\hline
\end{tabular}

Note: Number of $*$ denote significant differences (LSD test, $\mathrm{p}<0.05, \mathrm{p}<0.01, \mathrm{p}<0.001)$.

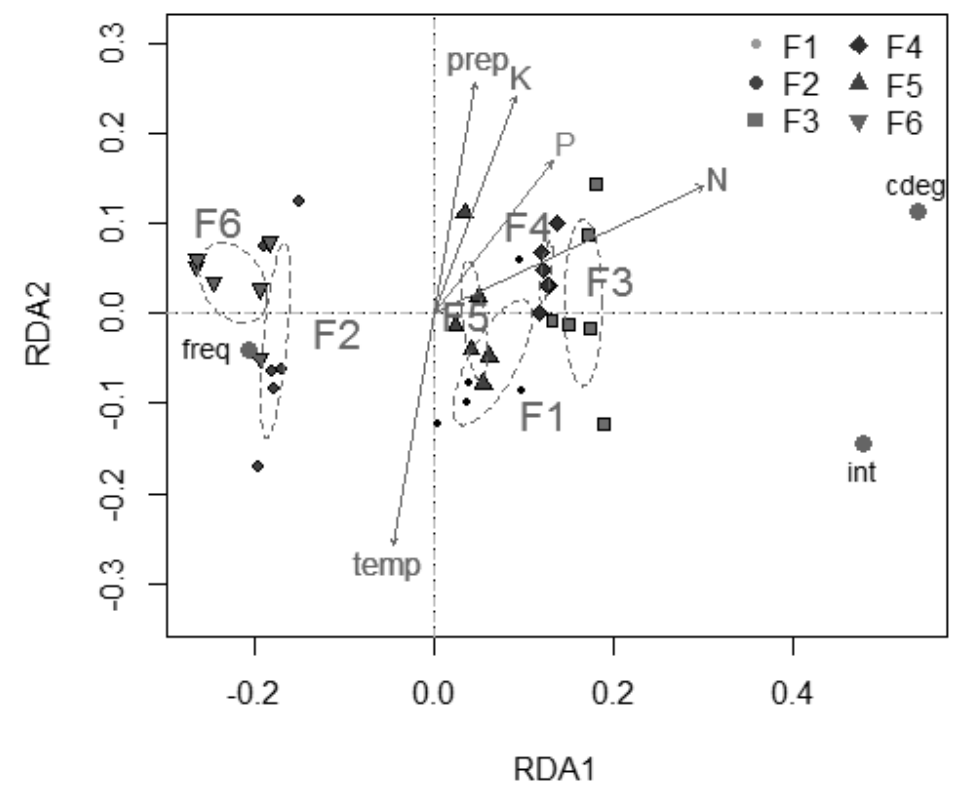

Fig. 1. Fertilization and mulching effect on colonization 
Tab. 2. Overlapping experimental factors on RDA graph

\begin{tabular}{lcccc}
\hline & \multicolumn{2}{c}{ Mulching } & \multicolumn{2}{c}{ Zinc sulphate } \\
\hline Factor & $\mathrm{r} 2$ & $\mathrm{Pr}>\mathrm{r}$ & $\mathrm{r} 2$ & $\mathrm{Pr}>\mathrm{r}$ \\
\hline temp & 0.4417 & $0.001^{* * *}$ & 0.3324 & $0.004^{* *}$ \\
\hline prep & 0.4417 & $0.001^{* * *}$ & 0.3324 & $0.004^{* *}$ \\
\hline $\mathrm{N}$ & 0.7085 & $0.001^{* * *}$ & 0.7644 & $0.001^{* * *}$ \\
\hline $\mathrm{P}$ & 0.2971 & $0.005^{* *}$ & 0.6391 & $0.001^{* * *}$ \\
\hline $\mathrm{K}$ & $0.4327^{* * *}$ & $0.001^{* * *}$ & 0.4846 & $0.001^{* * *}$ \\
\hline
\end{tabular}

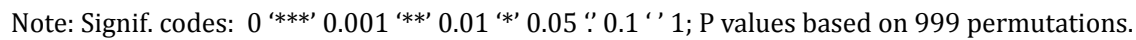

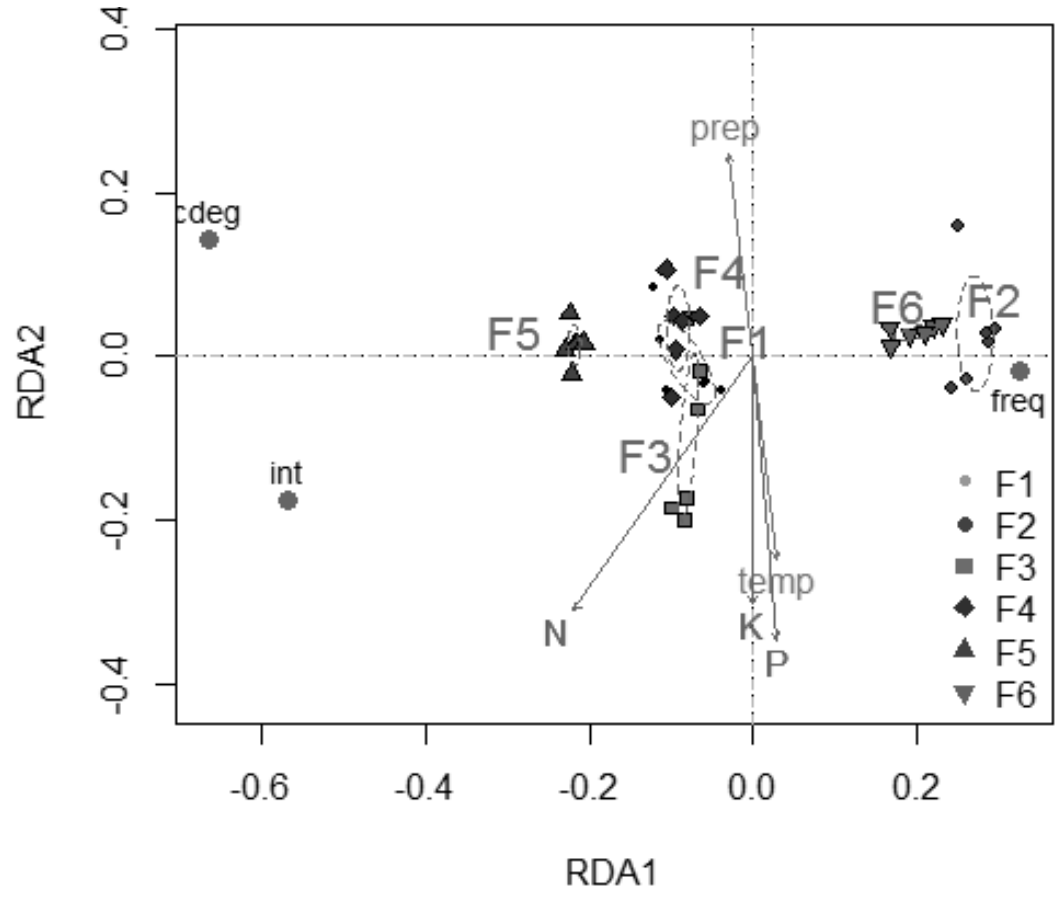

Fig. 2. The effect of fertilization and zinc sulphate on colonization

intensity is much enhanced by fertilization with manure supplemented with mineral nitrogen(F3) or mulching without fertilization (F1).

Due to mycorrhizal fungi specialization for particular phosphorus absorption from less accessible forms for plants, the amount of phosphorus in the ecosystem brought by fertilization had less effect than the other minerals, the effect being amplified by the climate (Tab. 2).

At potentiation of the effect of zinc sulfate application on mycorrhizal colonization, have contributed to a greater extent the elements contained in the mineral fertilizer recipes than the climate in the experimental area (Tab. 2).
In the ordination graph, frequency of colonization is located within range of organic fertilization (F2) and recipe based on Eurofertil mezocalc (F6), much closer to the F2 fertilization area of action, and overlapping zinc sulphate on those fertilization produced strong decrease of frequency (Fig. 2).

For colonization intensity part and the degree of colonization during the period of experimentation proved beneficial fertilizations with mineral nitrogen (F3, F4 and F5), the parameter being close to the gradient of nitrogen in the RDA graph (Fig. 2), from all the three fertilization recipes the one with microelements was more beneficial (F5). 


\section{CONCLUSION}

Mulching and zinc sulfate acts to reduce the values of colonization degree if it overlapping on an organic fertilization or mineral fertilization without nitrogen.

Under the same fertilization conditions zinc sulfate acts, generally, to double the intensity and the colonization degree compared to mulching, and the maximum frequency is obtained only in the case of zinc sulphate application.

Climate elements such as temperature and precipitation potentiates the effect of zinc sulfate applied with fertilizer, however, in the case of mulching the effect is less pronounced, being equal to the effect of fertilization.

\section{REFERENCES}

1. Birhane E, Sterck FJ, Fetene M, Bongers F and Kuyper TW (2012). Arbuscular mycorrhizal fungi enhance photosynthesis, water use efficiency, and growth of frankincense seedlings under pulsed water availability conditions. Oecologia 169: 895-904.
2. Dörmann P, Kim H, Ott T, Schulze-Lefert P, Trujillo M, Wewer V, Hückelhoven R (2014), Cell-autonomous defense, re-organization and trafficking of membranes in plant-microbe interactions. New Phytologist. doi: 10.1111/nph.12978.

3. Ehrmann J, Ritz K (2013) Plant: soil interactions in temperate multi-cropping production systems. Plant Soil: 1-29.

4. Goh C-H, Veliz Vallejos DF, Nicotra AB, Mathesius U (2013) The impact of beneficial plant-associated microbes on plant phenotypic plasticity. J Chem Ecol 39:826-839.

5. Hodge A, Storer K (2014). Arbuscular mycorrhiza and nitrogen: implications for individual plants through to ecosystems. Plant Soil DOI 10.1007/s11104-014-2162-1.

6. Oksanen J, Blanchet FG, Kindt R, Legendre P, Minchin PR, O'Hara RB, Simpson GL, Solymos P, Stevens MHH, Wagner H (2013) Vegan: community ecology package. R package version 2.0-10.

7. R Core Team (2014). R: A language and environment for statistical computing. R Foundation for Statistical Computing, Vienna, Austria.

8. STATSOFT, INC. (2012). Electronic Statistics Textbook. Tulsa, OK: StatSoft. WEB: http://www.statsoft.com/ textbook/. 